\title{
Analysis of Covid - 19 Situations in Davanagere District, Karnataka
}

\author{
Gouri Sakre $^{1 *}$, Gulappa Devagappanavar ${ }^{2}$ \\ ${ }^{1}$ Master of Public Health Scholar, Panchayat Raj University, Gadag, Karnataka, India. \\ ${ }^{2}$ Guest Faculty, Karnataka, India.
}

*Corresponding Author: Gouri Sakre, School of Environmental Science, Public Health and Sanitation Management. Karnataka State Rural Development and Panchayat Raj University, Gadag, Karnataka, India.

Received date: April 29, 2021: Accepted date: August 16, 2021: Published date: August 28, 2021

Citation: Sakre G, Devagappanavar G. (2021) Analysis of Covid - 19 Situations in Davanagere District, Karnataka J. of Clin Case Rep and Stu 2(4); DOI: $10.31579 / 2690-8808 / 076$

Copyright: (C) 2021: Gouri Sakre. This is an open access article distributed under the Creative Commons Attribution License, which permits unrestricted use, distribution, and reproduction in any medium, provided the original work is properly cited.

\begin{abstract}
Background: According to CDC, Coronavirus disease 2019 (COVID-19) is caused by a new coronavirus which was first identified in Wuhan, China, in December 2019. Although most people who have COVID-19 have mild symptoms, it can also cause severe illness and even death. Some groups, including older adults and people who have certain underlying medical conditions, are at increased risk of severe illness. On February 11, 2020, the World Health Organization announced an official name for the disease that is causing the 2019 novel coronavirus outbreak. The new name of this disease is coronavirus disease 2019, abbreviated as COVID-19.
\end{abstract}

Objectives: Analysis of COVID 19 data in the Davanagere district from April 2020 to August 2020.

Methods: In this current study the secondary data is obtained from the Official Website of Government of Karnataka, Covid19 Informational Portal - Media Bulletin. By using different indicators Davanagere district covid data is further used to calculate Attack rate, Case fatality rate and complete case fatality rate.

Results: In this study it is found that, in the month of April there were no covid positive cases reported till fourth week of month, by fourth week, total two positive cases were reported the first case being encountered on $28^{\text {th }}$ April 2020, with discharge of those patient in the end of the month. The attack rate has steeped up from 8.018 to 355.74 per one lakh population i.e. about 44 times more than initial months of pandemic. The strict preventive measures were followed by public and government too. So the prevalence rate is less in May, June and went on increasing once the unlocking is done. In summer the total positive cases steeping up from 2 cases to 154 total positive cases for the month April to May, and there is steady in rise of total positive cases for the month June with total positive cases of 153. In the beginning of summer there were fewer cases as pandemic was just begun and chances of transmission were very less. As monsoon appeared in June last week there is surge in total positive cases. With added burden of Unlock 1.0 phase, as public started moving out from home without any freak of infection.

Conclusion: In this study it is found that due to strict nationwide lockdown and social distancing, hygiene practices among the Davanagere people has made it possible to restrict the spread of covid among the people, although the international immigration of Davanagere residents lead to transmission of infection. Further removal of lockdown after three months has lead to three fold spread of disease. Also there is rise in death rate, attack rate and case fatality in Davanagere district.

Key words: COVID-19, corona, SARS-CoV, prevalence, CFR, south india

\section{Introduction}

Definition: According to Merriam Webster,Covid-19 is defined as a mild to severe respiratory illness that is caused by a coronavirus (of the genus Betacoronavirus), is transmitted chiefly by contact with infectious material (such as respiratory droplets) or with objects or surfaces contaminated by the causative virus, and is characterized especially by fever, cough, and shortness of breath and may progress to pneumonia and respiratory failure. OR Coronavirus disease 2019 (COVID-19) is a potentially severe acute respiratory infection caused by 
severe acute respiratory syndrome coronavirus 2 (SARS-CoV-2). The virus has been found to be similar to severe acute respiratory syndrome (SARS)-like coronaviruses from bats, but it is distinct from SARS-CoV and Middle East respiratory syndrome (MERS)-CoV [1].

\section{How the Covid-19 Pandemic has begun}

The virus was identified as the cause of an outbreak of pneumonia of unknown cause in Wuhan City, Hubei Province, China, in December 2019. Wuhan city is a major transportation hub with a population of more than 11 million people. Most of the patients visited a local fish and wild animal market on December [2].

The clinical presentation is that of a respiratory infection with a symptom severity ranging from a mild common cold-like illness, to a severe viral pneumonia leading to acute respiratory distress syndrome that is potentially fatal.

Since then, the outbreak has escalated rapidly, with the WHO declaring a public health emergency of international concern on 30 January 2020.

\section{Etiology}

SARS-CoV-2 is a previously unknown betacoronavirus that was discovered in Broncho-alveolar lavage samples taken from clusters of patients who presented with pneumonia of unknown cause in Wuhan City, Hubei Province, China, in December 2019.

Coronaviruses are a large family of enveloped RNA viruses, some of which cause illness in people (e.g., common cold, SARS, MERS), and others that circulate among mammals (e.g., bats, camels) and birds.

Rarely, animal coronaviruses can spread to humans and subsequently spread between people, as was the case with SARS and MERS. A majority of patients in the initial stages of this outbreak reported a link to the Huanan South China Seafood Market, a live animal or 'wet' market, suggesting a zoonotic origin of the virus.

\section{Signs and Symptoms}

\section{Clinical presentation}

The clinical presentation resembles viral pneumonia, and the severity of illness ranges from mild to severe. Most patients present with mild illness. Approximately $20 \%$ of symptomatic patients may progress to severe illness. Some patients may be minimally symptomatic or asymptomatic, with most patients being healthy adults.

Based on an early analysis of case series, the most common symptoms are:

- The commonest, telltale symptom of COVID-19 was low-grade fever that gradually worsens over time.

- $\quad$ Cough and myalgia (muscle pain): while cough is typically the first symptom of the seasonal flu, it often appears second in covid-19 cases. Common symptoms include cough, fever, dyspnea, and musculoskeletal symptoms - Myalgia, joint pain, and fatigue, gastrointestinal symptoms, and anosmia/dysgeusia. [In Italy, as of June 3, 2020]

- Nausea or vomiting: the onset of nausea, vomiting, and diarrheal after onset of respiratory symptoms such as cough and fever may also suggest that a person may have Covid-19 (Dr. Robert Glatter, Lenox Hill Hospital)

- Sputum production, headache and diarrhoea were rare presentations. Acute respiratory distress syndrome (ARDS), anaemia, secondary infection, and acute cardiac injury were common complications noted more in patients needing intensive care. [In Wuhan, Hubei, China as of December 2019]

- Loss of smell, skin rashes, eye infection (conjunctivitis also called pinkeye has been reported in some people with coronaviruswww.webmd.com, 23 ${ }^{\text {rd }}$ May 2020).
- Hypoxia and viral carditis are the symptoms observed, severe backache, abdominal pain, aching calves were also noted.

- Neurological signs like Encephalopathy, Encephalitis and GuillainBarre syndrome are being associated.

- The study in Gujarat has been observed that the well-known risk of clotting of blood vessels prolongs for weeks in some patients an important complication.

This makes recovered patients susceptible for heart attacks, brain strokes and pulmonary embolism leading to sudden deaths. Persistent Hiccups as atypical presentation of COVID is the recent symptom added.

Approximately $90 \%$ of patients present with more than one symptom, and $15 \%$ of patients present with fever, cough, and dyspnea. It appears that fewer patients have prominent upper respiratory tract or gastrointestinal symptoms compared with SARS, MERS, or influenza [3].

\section{Transmission}

Person-to-person spread has been confirmed in community and healthcare settings in China and other countries. An initial assessment of the transmission dynamics in the first 425 confirmed cases found that $55 \%$ of cases before 1 January 2020 were linked to the Huanan South China Seafood Market, whereas only $8.6 \%$ of cases after this date were linked to the market. This confirms that person-to-person spread occurred among close contacts since the middle of December 2019, including infections in healthcare workers. Nosocomial transmission in healthcare workers and patients has been reported in $41 \%$ of patients in one case series.

\section{Materials and Methods}

\section{Study design:}

In this study the current the secondary data is obtained from the Official Website of Government of Karnataka, Covid-19 Informational Portal Media Bulletin. By using different variables Davanagere district covid data is further used to calculate Attack rate, Case fatality rate and complete case fatality rate.

\section{Study setting:}

In this study Covid-19 secondary data of Davanagere district was obtained from $16^{\text {th }}$ April to $31^{\text {st }}$ August 2020 from Media Bulletin of Government of Karnataka.

\section{Variables:}

The different variables like total positive cases, today's positive cases, total discharge, today's discharge, active cases and covid deaths of Davanagere district is obtained.

\section{Study size:}

The cumulative data of Davanagere district covid and on daily basis pandemic spread, the total positive cases, total discharge cases, total covid death is procured for further calculation of prevalence. Daily additional cases of these variables are also acquired.

\section{Statistical method:}

Data was entered into excel sheet, analyzed and expressed in frequency and percentages.

\section{Result}

\section{Trends and patterns of COVID-19 - Davanagere district}

In this study, statistical analysis of Covid cases in Davanagere district is done as follows.

Week-wise analysis of trends and patterns of Covid-19 from April 2020 to August 2020. 


\begin{tabular}{|l|l|l|l|}
\hline Weeks & Total Positive & Total Discharge & Total Covid deaths \\
\hline 1st week & 0 & 0 & 0 \\
\hline 2nd week & 0 & 0 & 0 \\
\hline 3rd Week & 0 & 0 & 0 \\
\hline 4th week & 2 & 2 & 0 \\
\hline
\end{tabular}

Table 1: Week wise distribution of covid-19 cases of month April.

In the month of April there were no covid positive cases reported till reported the first case being encountered on $28^{\text {th }}$ April 2020 , with fourth week of month, by fourth week, total two positive cases were

discharge of those patient in the end of the month.

\begin{tabular}{|l|l|l|l|}
\hline May & Total positive & Total Discharge & Total covid death \\
\hline 1st week & 47 & 2 & 3 \\
\hline 2nd week & 88 & 2 & 4 \\
\hline 3rd week & 115 & 14 & 4 \\
\hline 4th week & 142 & 79 & 4 \\
\hline 5th week & 156 & 121 & 4 \\
\hline
\end{tabular}

Table 2: Week wise distribution of covid-19 cases of month May.

In this study it is found that, in May month the total positive cases has steeping up from $1^{\text {st }}$ week to $5^{\text {th }}$ week, from 47 cases during first week to 156 infected cases by fifth week, where discharge rate is also seen rising

\begin{tabular}{|l|l|l|l|}
\hline June & Total positive & Total Discharge & Total covid death \\
\hline 1 st week & 203 & 150 & 6 \\
\hline 2nd week & 226 & 194 & 6 \\
\hline 3rd week & 256 & 220 & 7 \\
\hline 4th week & 295 & 246 & 7 \\
\hline 5th week & 309 & 265 & 8 \\
\hline
\end{tabular}

Table 3: Week wise trends and patterns of covid-19 of June month

In the month June 2020, there was not much rise in infected cases from first week to fifth week it is seen that there is rise of hundred cases from starting to end of the month. It is also seen similar in the total recovered

\begin{tabular}{|l|l|l|l|}
\hline \multicolumn{1}{|c|}{ July } & Total positive & Total Discharge & Total covid death \\
\hline 1st week & 365 & 311 & 13 \\
\hline 2nd week & 598 & 468 & 22 \\
\hline 3rd week & 880 & 541 & 30 \\
\hline 4th week & 1668 & 963 & 41 \\
\hline 5th week & 2101 & 1202 & 48 \\
\hline
\end{tabular}

Table 4: Week wise trends and patterns of covid-19 of July month

There is sudden surge of cases in the month of July due to the first phase of unlock 2.0 started from $1^{\text {st }}$ July. So the incidence of cases was also increased. Due to unlock people started moving around which increased the cases. There is seven fold increases in the infection rate from

\begin{tabular}{|l|l|l|l|}
\hline \multicolumn{1}{|c|}{ August } & Total positive & Total Discharge & Total covid death \\
\hline 1st week & 3151 & 2048 & 78 \\
\hline 2nd week & 4756 & 3153 & 120 \\
\hline 3rd week & 6508 & 4388 & 148 \\
\hline 4th week & 8538 & 6236 & 178 \\
\hline 5th week & 9487 & 7003 & 191 \\
\hline
\end{tabular}

beginning of the week to till last week. I.e. total positive cases steeped up death were 48 by the end of July 2020 . from 365 to 2101. It is noticed that total recovery rate or discharge of Covid cases is from 365 to 1202 . And it is also reported that total covid

cases which also has a difference of nearly hundred discharged cases. Totally eight deaths due to covid were reported by the end of the month.

up compared to case of positive. There were total four covid deaths by the end of May 2020. 
In this study it is found that by the end of August 2020, there is rapid rise in the incidence of covid cases with weekly piling up of about 1000-1500 cases. Recovery rate is also quiet appreciating, by last week of this month the total discharge of covid cases is about 7003. It is reported there were total 191 deaths due to Covid.

\section{Mortality and Morbidity Indicators.}

In this current study the attack rate, case fatality rate and complete case fatality rate is determined as follows -

Attack rate is the ratio of the number of people who become ill to the number of people at risk for the illness or in other words it is the percentage of an at-risk population that contracts the disease during a specified time interval.

Case fatality rate is the proportion of deaths from a certain disease compared to the total number of people diagnosed with the disease for a particular disease. It is conventionally expressed as a percentage and represents a measure of disease severity.

Complete case fatality rate is proportion of death among the population who got infected with the specific disease. It is calculated as number of death due to specific disease divided by summation of death and recoveries from same disease. It is always expressed in percentage.

\begin{tabular}{|l|l|l|l|}
\hline Months & Attack rates & CFR & CCFR \\
\hline May & 8.018 & $2.59 \%$ & $35.39 \%$ \\
\hline June & 15.88 & $2.61 \%$ & $35.62 \%$ \\
\hline July & 84.09 & $2.48 \%$ & $375.98 \%$ \\
\hline August & 355.74 & $1.94 \%$ & $1590.57 \%$ \\
\hline
\end{tabular}

Table 6: Comparison of attack rates, case fatality rate and complete case fatality rate.

There is steeping up in the attack rate from May to August is seen, as there was Nationwide lockdown in the initial months of pandemic. So the positive cases in Davanagere were not soo high. The lockdown for 21 days is started from $24^{\text {th }}$ march 2020 and it is further continued into 4 phases till $31^{\text {st }}$ may 2020.

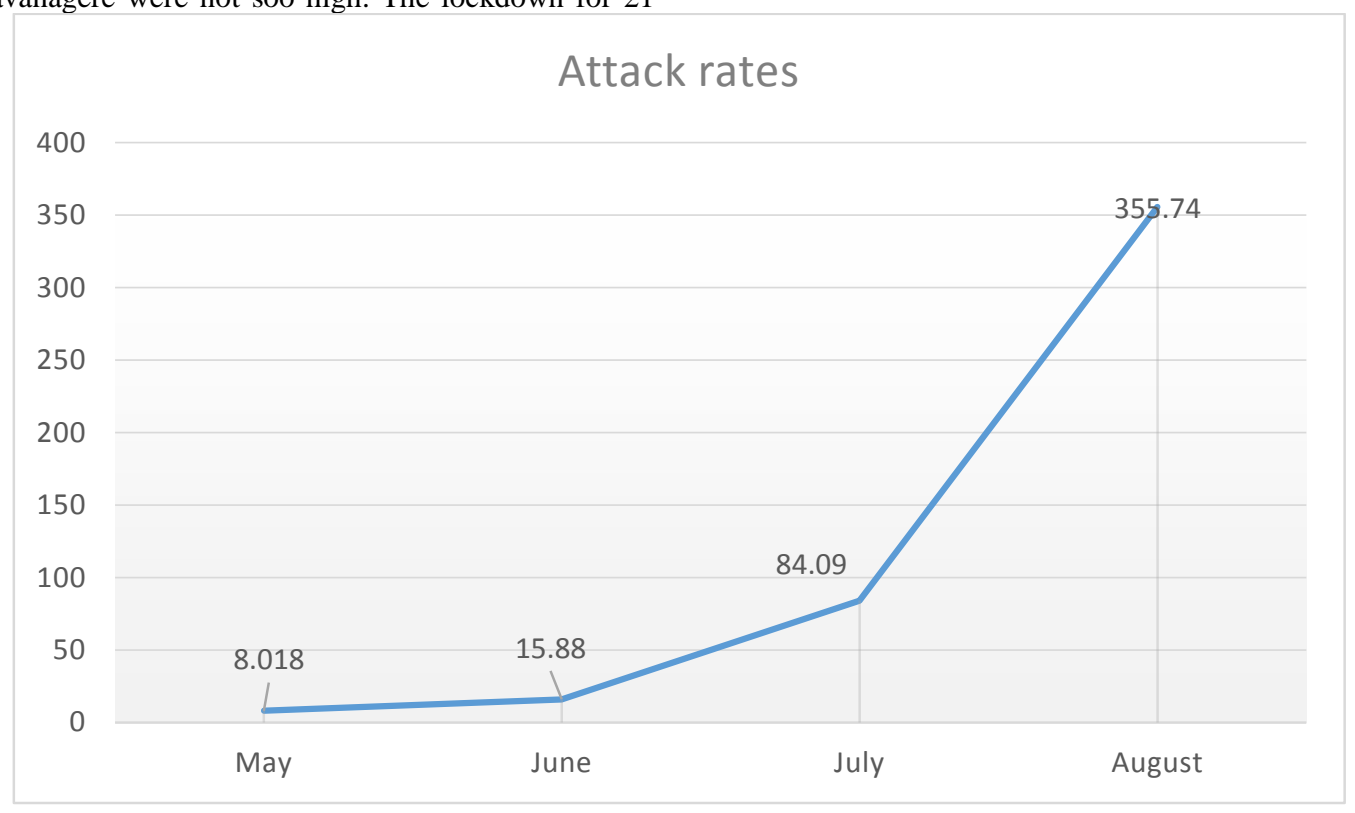

Graph 1: Attack rates of Covid19 from May to August

The attack rate has steeped up from 8.018 to 355.74 per one lakh population i.e. about 44 times more than initial months of pandemic. The strict preventive measures were followed by public and government too.
So the prevalence rate is less in May, June and went on increasing once the unlocking is done. 


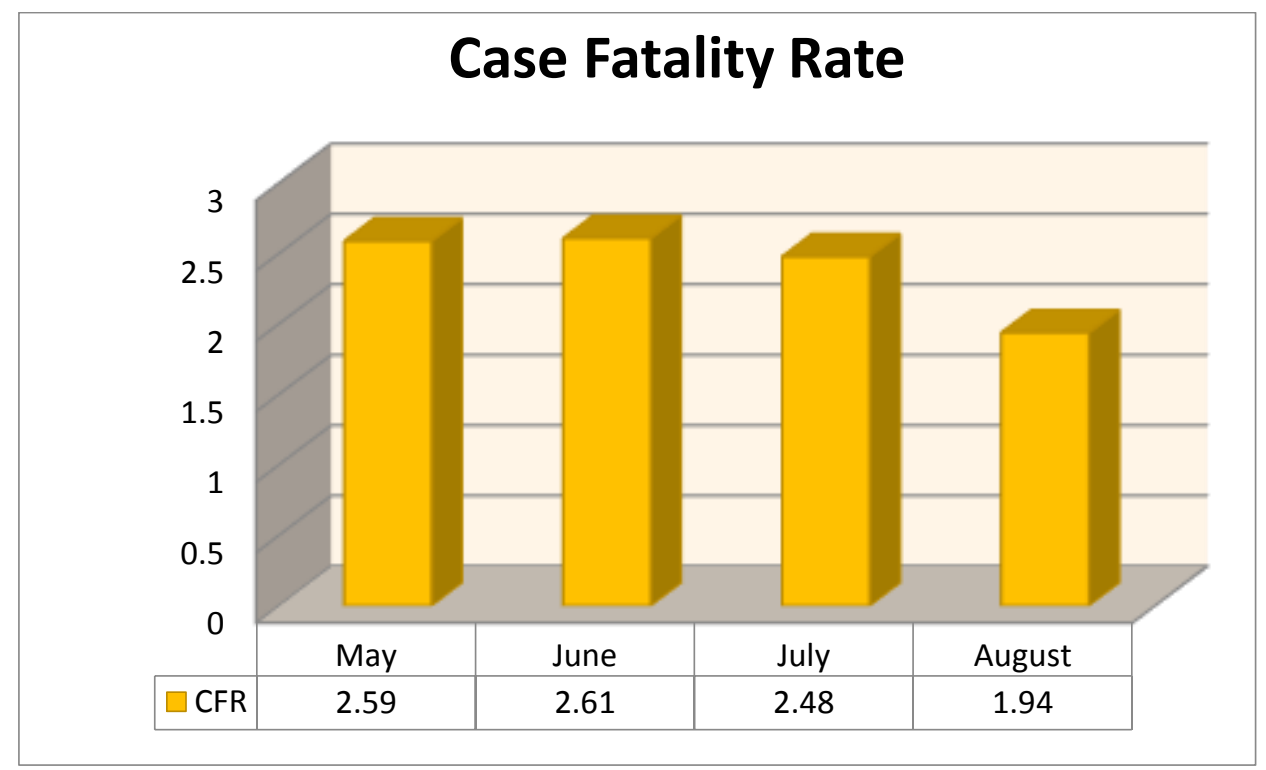

Graph 2: Case fatality rate of covid19 from May to August

The case fatality rate on the month of May is $2.59 \%$ which were alleviated for about $0.2 \%$ by the month of June and the decreased by the July month. And by august the case fatality rate has fell down to $1.94 \%$. In this study we can see that the CFR of Covid in Davanagere district has kept on
Steeping down against the rising positive cases. The CFR kept on decreasing against the increasing incidence rate.

This might be due to the awareness among the public for pandemic; the strict rules were followed so the case fatality rate was well maintained.

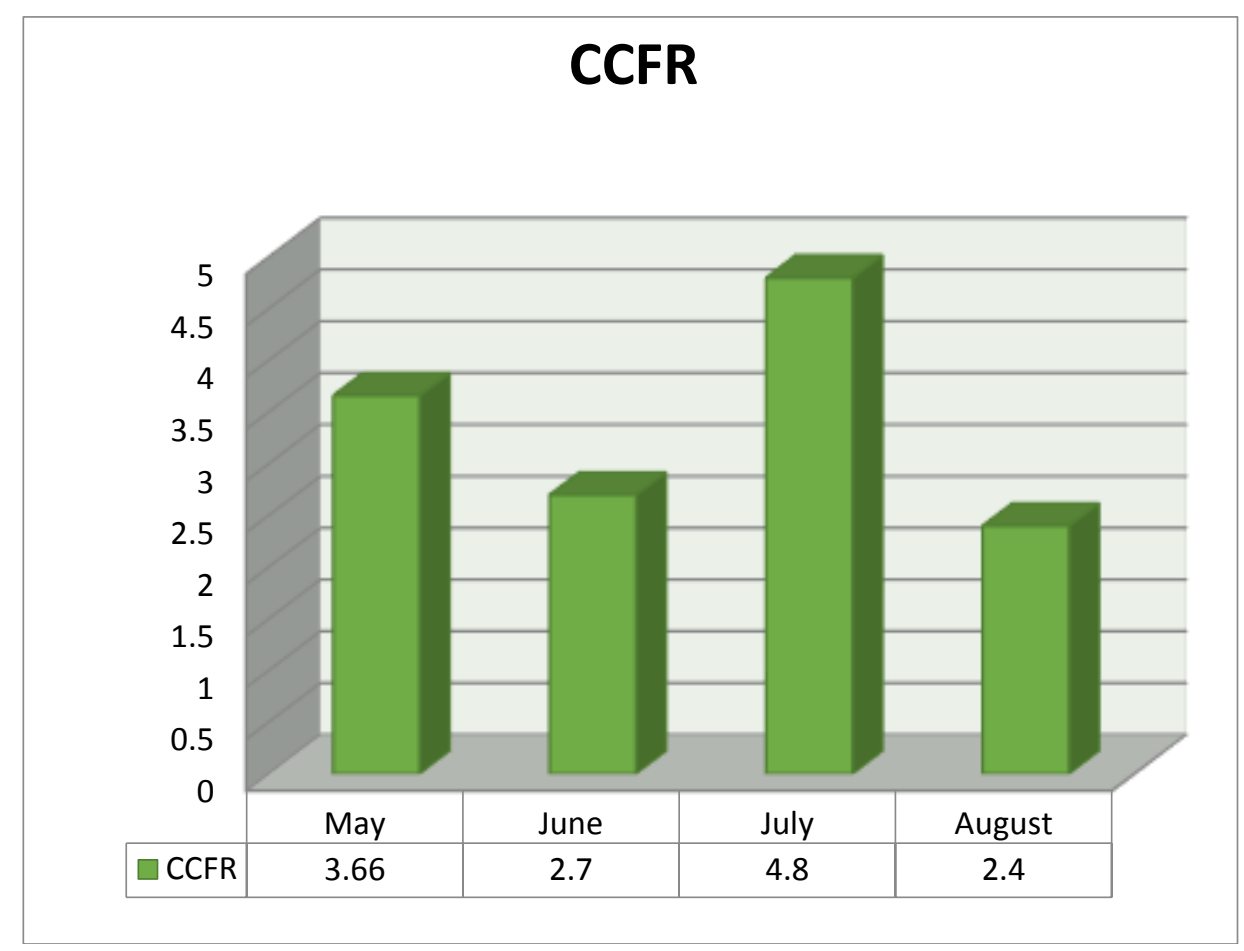

\section{Graph 3: CCFR of Covid19 from May to August}

The complete case fatality rate is also seen steeping down from May to August i.e. $3.66 \%$ to $2.4 \%$. Number of recovered cases has also kept on steeping up. This is due to early detection and isolation of cases and appropriate symptomatic treatment. In this study the CCFR of Davanagere district is seen decreasing as the days progress.

\section{Seasonal trend Analysis of covid 19}




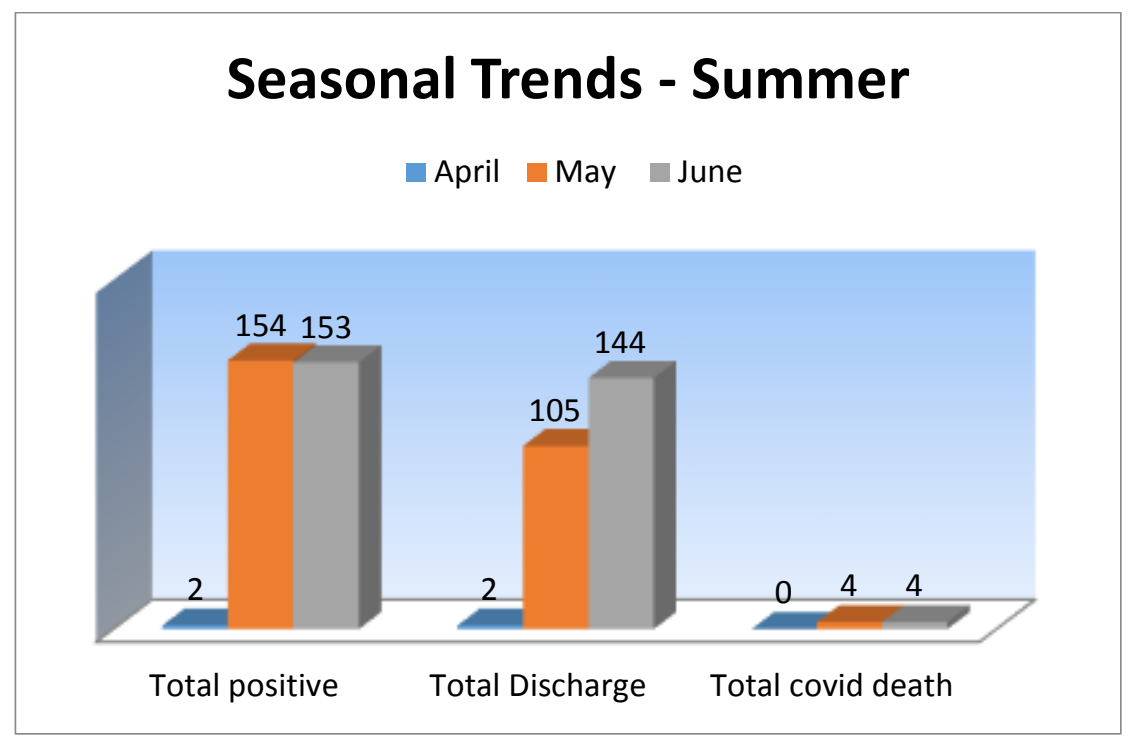

Graph 4: Seasonal trends analysis of Covid-19 in summer

In summer the total positive cases steeping up from 2 cases to 154 total positive cases for the month April to May, and there is steady in rise of total positive cases for the month June with total positive cases of 153. In the beginning of summer there were fewer cases as pandemic was just begun and chances of transmission were very less. As monsoon appeared in June last week there is surge in total positive cases. With added burden of Unlock 1.0 phase, as public started moving out from home without any freak of infection.

Number of total discharge or recovery of covid cases is also surged up from April to June 2020, from 2 discharges to 144 cases, the number of total covid deaths remained steady as of summer there were only four covid deaths. 


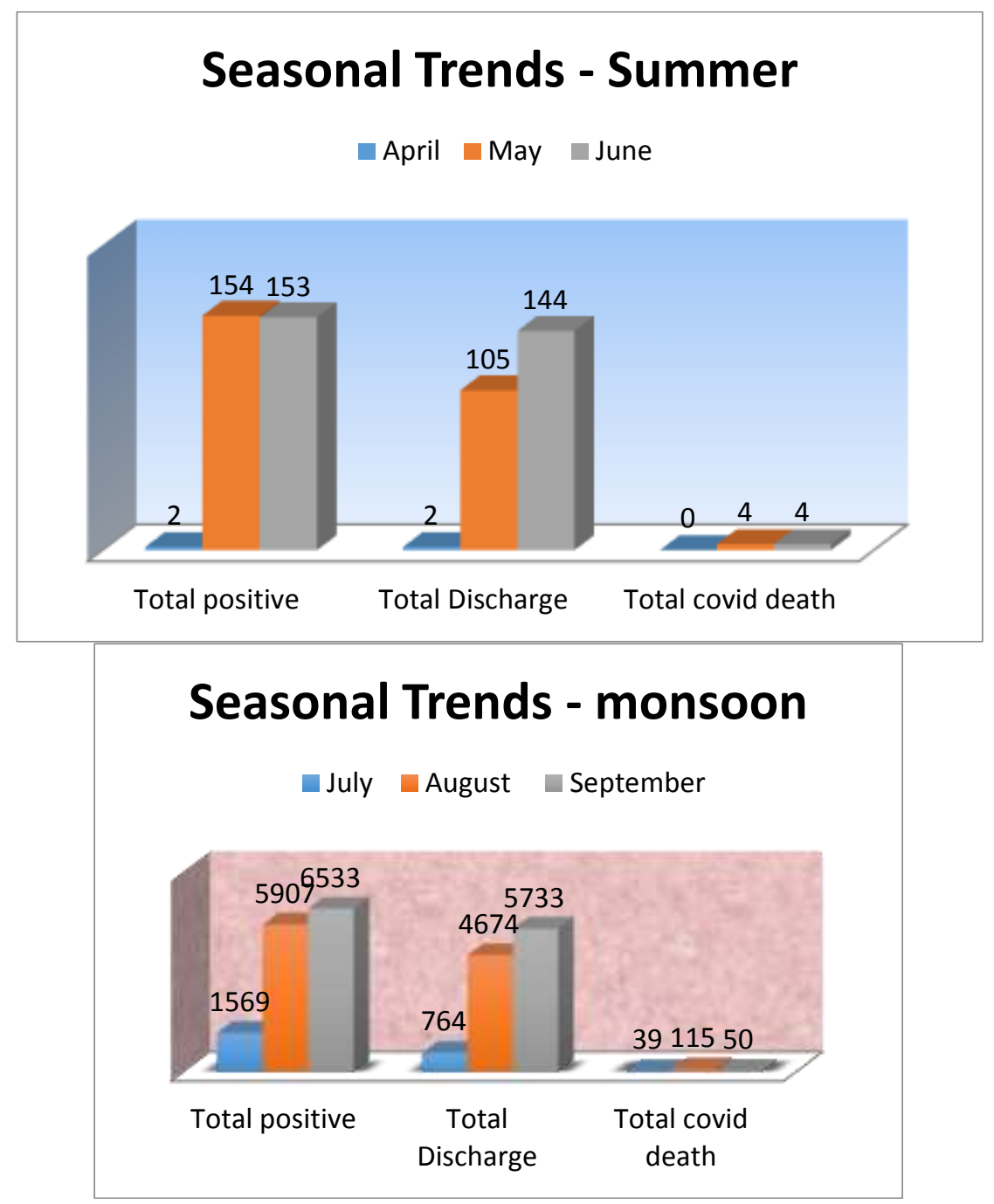

Graph 5: Seasonal trend analysis of Covid-19 in Monsoon

In monsoon season the total covid positive cases has begun to surge rapidly, from 153 cases to 1569 cases, from June to July. As the positive cases have rouse at the rate of ten times, the total discharge of covid cases has also increased. This is due to better preventive measures among the individuals; even due to fear to death many have practiced good respiratory hygiene. This might have led to increase in discharge from hospital.

In Davanagere district total covid death is well maintained and has seen a lot of ups and downs. There were only four cases in summer season and rise to 39 in initial stage of monsoon. As monsoon preceded the covid death cases were up surged to 115 and fell down to 50 cases in the end of monsoon.

\section{Discussion}

Davanagere District is an administrative district of Karnataka state in India. The city of Davanagere is the district headquarters. Davanagere district lies in the plain region on the Deccan Plateau locally known as Bayalu Seeme. Davanagere city had a population of $19,45,497$, with total area of $5924 \mathrm{Sq} \mathrm{Km}$. And has two revenue divisions. There are six taluks under the Davanagere district. The prominent towns in this district are Harihara, Jagaluru, Harappanahalli, Honnali and Channagiri.
The present study is done with regards to statistical analysis of COVID 19 data in Davanagere district (from April 2020 to August 2020). Data is being collected by the official website from Government of Karnataka. Due to awareness among public and strict local government rules the people wore the mask lead to well manage of death due to covid. There is also active preventive measures took up by the Public health and good hospital facilities.

In a similar study it is found that the outbreak of SARS-CoV-2 and its corresponding diseases COVID-19 has received diverse responses from different countries. Countries like India, China and Australia have imposed partial to full nation-wide lock-downs leading to mixed repercussions. Other countries like Sweden have imposed little to no restrictions. Such factors definitely affect the distribution of cases and hence the curve parameters. Moreover, there is bias in data due to diverse travel histories and contact demographic histories of people from Wuhan [8].

In this study it is found that the attack rate has steeped up from 8.018 to 355.74 per one lakh population i.e. about 44 times more than initial months of pandemic. The strict preventive measures were followed by public and government too. So the prevalence rate is less in May, June and went on increasing once the unlocking is done. 
The case fatality rate on the month of May is $2.59 \%$ which were alleviated for about $0.2 \%$ by the month of June and the decreased by the July month. And by august the case fatality rate has fell down to $1.94 \%$. In this study we can see that the CFR of Covid in Davanagere district has kept on Steeping down against the rising positive cases. The CFR kept on decreasing against the increasing incidence rate.

The complete case fatality rate is also seen steeping down from May to August i.e. $3.66 \%$ to $2.4 \%$. Number of recovered cases has also kept on steeping up. This is due to early detection and isolation of cases and appropriate symptomatic treatment. In this study the CCFR of Davanagere district is seen decreasing as the day progress.

\section{Conclusion}

In this study it is found that due to strict nationwide lockdown and social distancing, hygiene practices among the Davanagere people has made it possible to restrict the spread of covid among the people, although the international immigration of Davanagere residents lead to transmission of infection.

Further removal of lockdown after three months has lead to three fold spread of disease. Also there is rise in death rate, attack rate and case fatality in Davanagere district.

Although in later months of the pandemic it is seen there is hike in the positivity rate and attack rate of the covid cases in Davanagere district. So the strict action about rapid infectivity is to be considered, awareness about preventive measures to be promoted among the public, regulatory measures must be made from the government to curb the allover spread of infection.

\section{Recommendation}

1. To reduce the spread of covid immigration and emigration should be properly monitored.

2. Regulatory measures to be taken against mass gathering of the people.

3. Wearing mask and maintaining social distance should be made strict in the district.
4. Hygiene practices like hand washing and bathing, use of sanitizer is to be practiced as the preventive measure.

\section{References}

1. Covid 19 (2020).

2. Rothan HA, Byrareddy SN. (2020). The epidemiology and pathogenesis of coronavirus disease (COVID-19) outbreak. J Autoimmun;

3. Suresh K. (2020). Covid 19-India : Enigma of Saving Lives or Economy.;19.

4. Cas C. (2020). India's 1st coronavirus case reported in Kerala; 19.

5. Searches T, Casesbangalore C, Deals TOP. (2020). Karnataka's 1st Covid-19 case, Bengaluru techie tests positive.;19

6. Toi MF, App O. (2020). After four-week lull, third Covid-19 case in Davanagere.;

7. Deb S. A time series method to analyze incidence pattern and estimate reproduction number of COVID-19:1-14.

8. Tuli S, Tuli S, Tuli R, Gill SS. (2020). Predicting the growth and trend of COVID-19 pandemic using machine learning and cloud computing. Internet of Things; 11:100222

9. Joe W, Kumar A, Rajpal S, Mishra US. (2020). Equal risk , unequal burden ? Gender differentials in COVID-19 mortality in India;2(1):1-15

10. Baruah HK. (2020). The Current COVID-19 Spread Pattern in India.;6-10

11. Mohak A, Mohanta SS, Rao A, Parameswaran GG, Agarwal M, et al. (2020). Transmission dynamics of the COVID - 19 epidemic in India and modelling optimal lockdown exit strategies Original Research Article;1-20

12. Devagappanavar G. (2020). Impact of corona virus disease outbreak on;24(104).

13. Wilson W, Raj JP, Rao S, Ghiya M, Nedungalaparambil NM, et al. (2020) . Depression among Healthcare Workers Managing COVID-19 Pandemic in India: a Nationwide Observational Study.;42(4).

14. Poudel K. (2020). Impact of COVID-19 pandemic on socioeconomic and mental health aspects in Nepal.

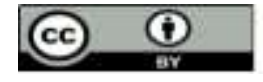

This work is licensed under Creative Commons Attribution 4.0 License

To Submit Your Article Click Here: Submit Manuscript

DOI: $10.31579 / 2690-8808 / 076$
Ready to submit your research? Choose Auctores and benefit from:

* fast, convenient online submission

* rigorous peer review by experienced research in your field

* rapid publication on acceptance

* authors retain copyrights

* unique DOI for all articles

* immediate, unrestricted online access

At Auctores, research is always in progress.

Learn more auctoresonline.org/journals/journal-of-clinical-case-reportsand-studies 